DOE/ER/63215

\title{
GLOBAL LAND USE DATA \\ FOR INTEGRATED ASSESSMENT MODELING
}

\author{
Final Report \\ for Period Sept 15, 2001 - Sept 14, 2005 \\ Navin Ramankutty \\ Center for Sustainability and the Global Environment (SAGE) \\ Gaylord Nelson Institute for Environmental Studies \\ University of Wisconsin-Madison \\ 1710 University Avenue \\ Madison, WI 53726
}

Dec 2005

Prepared for

\section{THE U.S. DEPARTMENT OF ENERGY \\ AWARD NO. DE-FG02-01ER63215}

This report was prepared as an account of work sponsored by the United States Government. Neither the United States nor the United States Department of Energy, nor any of their employees, nor any of their contractors, subcontractors, or their employees, makes any warranty, express or implied, or assumes any legal liability or responsibility for the accuracy, completeness, or usefulness of any information, apparatus, product, or process disclosed or represents that its use would not infringe privately-owned rights. 


\begin{abstract}
Changes in land use and land cover have been one of the major drivers of global change over the last three centuries. Detailed spatially-explicit data sets characterizing these historical land cover changes are now emerging. By synthesizing remotely-sensed land cover classification data sets with historical land use census data, our research group has developed comprehensive databases of historical land use and land cover change. Moreover, we are building estimates of the land suitability for agriculture to predict the constraints on future land use. In this project, we have interacted with the Global Trade and Analysis Project (GTAP) at Purdue University, to adapt our land use data for use with the GTAP database, a baseline database widely used by the integrated assessment modeling community. Moreover, we have developed an interactive website for providing these newly emerging land use data products for the integrated assessment (IA) community and to the climate modeling community.
\end{abstract}




\section{FINAL REPORT}

Our project has accomplished two major tasks:

1. Working with the Global Trade and Analysis Project (GTAP) at Purdue University to adapt our land use data for the GTAP database.

2. Developed an interactive user-friendly website for disseminating our emerging land use products to the integrated assessment and climate modeling community.

Below, we briefly describe the methods and achievements.

\section{Development of Global Land Use Data Sets}

I worked with the Global Trade and Analysis Project (GTAP) at Purdue University to incorporate land use into their database. To make the SAGE land use data useful for global economic modeling, additional developments were made to the land use data:

1. A database of Global Agro-Ecological Zones (GAEZ) was developed to represent "land endowments" within each country in the GTAP database. The national land use data were thus disaggregated to consider 18 AEZs within each country.

2. Development of spatially-explicit crop yield and production data is still in progress. Therefore, as a provisional measure for the GTAP database, we derived yield and production information from a database obtained from FAO for 94 developing countries.

This product is currently being reviewed by the integrated assessment modeling community.

\section{Development of Web Site}

We have developed a website, IAMDATA (http://www.sage.wisc.edu/iamdata) (see figure 1), to allow users to interactively manipulating our land use data sets, and download it in easy-to-use formats. The website allows the user to download data in either spatially-explicit gridded format, or aggregated by administrative units (i.e., world macro regions). We have added several new variables (including data disaggregated by AEZ) on the website (Table 1).

Table 1. Status of data on website

\begin{tabular}{|l|l|}
\hline Variables & Year \\
\hline Land Area & N/A \\
\hline Population & 1990,1995 \\
\hline Land cover (6 types + other) by AEZ & 1992 \\
\hline Major crops (18 crops + others) by AEZ & 1992 \\
\hline Historical land cover (4 types + other) & 1700 to 1992, in 10-year intervals \\
\hline Potential natural vegetation by AEZ & \\
\hline Land suitability for cultivation by AEZ & \\
\hline
\end{tabular}

We have advertised this website during multiple talks given to economic modelers over the past year, including at the EPA in Washington D.C., and the EMF meeting in Snowmass, Colorado. It was also referred in a recent news release from the University of Wisconsin. We have fixed bugs and incorporated suggestions from users of the website. 


\section{Conclusions}

We have developed a website, IAMDATA, to disseminate our global land use data to global economic modelers. We have also incorporated our land use data within the GTAP database. We have worked with GTAP to make our land use data compatible with the needs of economic models.

Figure 1. Snapshot of front page of IAMDATA website.

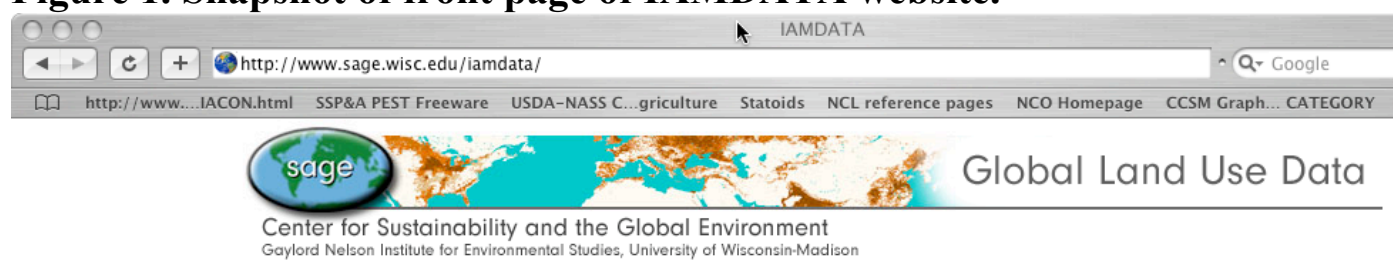

Global Land Use Database

This site provides access to our land use data. To read more generally about our work, please go to http://www.sage.wisc.edu/pages/landuse.html/ For a sneak preview of forthcoming data sets for the Year 2000, go to https://mywebspace.wisc.edu/clmonfreda/web/cropimages/.

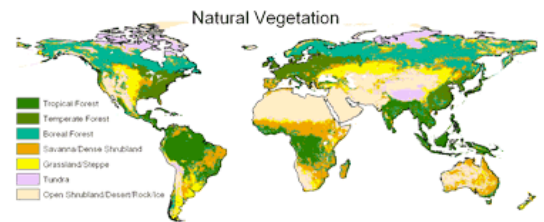

SAGE has been developing global databases of land use and land cover by combining satellite data and census data. This website provides access to our datasets of the distribution of the world's natural vegetation, croplands, grazing lands, major crops, etc.

Available Data

- Population density: 1990,1995

- Potential natural vegetation

- Cropland extent from 1700 to 1992

- Grazing land extent in 1992

- Built-up land extent in 1992

18 major crops extent in 1992
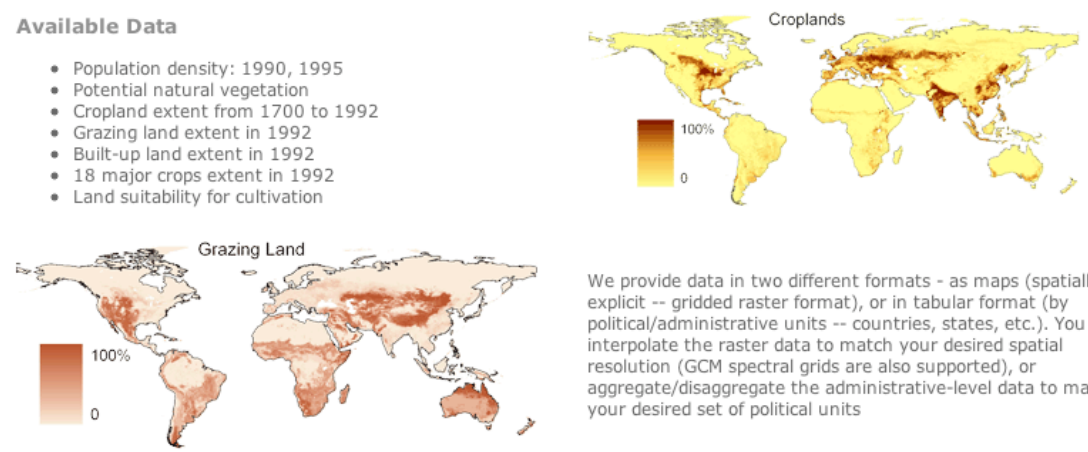

We provide data in two different formats - as maps (spatiallyexplicit -- gridded raster format), or in tabular format (by

political/administrative units -- countries, states, etc.). You can

interpolate the raster data to match your desired spatial

resolution (GCM spectral grids are also supported), or

aggregate/disaggregate the administrative-level data to match

your desired set of political units

Select the type of data that you would like to download.

Maps (gridded raster)

Finest Data Resolution is 0.5 degree in latitude by longitude.
Tabular (countries, states)

Maximum disaggergation has 2605 first-level administration units such as states and provinces. 